\title{
A Comparative Study of the Impact of Qualitative-Descriptive Evaluation and Quantitative Evaluation Methods on Academic Progress and Academic Motivation among Sixth Grade Students
}

\author{
Akram Sahraee \\ Department of Management, Boroujerd Branch Islamic Azad University, Boroujerd, Iran \\ E-mail: Akram.sahraee@gmail.com \\ Mohammad Jafar Mahdian (Corresponding Author) \& Hasan Dinarvand \\ Faculty of Islamic Azad University Boroujerd Branch - Boroujerd, Iran \\ E-mail: mjmahdian@yahoo.com
}

Received: August 7, 2015

Accepted: Oct. 8, 2015 Published: October 8, 2015

doi:10.5296/jmr.v7i5.8127

URL: http://dx.doi.org/10.5296/jmr.v7i5.8127

\begin{abstract}
The aim of the present research has been to comparatively study the impact of qualitative-descriptive evaluation and quantitative evaluation methods on the academic progress and academic motivation among sixth grade students in Mahidasht region in educational year 2014. Statistical population of the study included all the sixth grade students of Mahidasht region. From among the population of the study, 151 students were selected through convenience sampling, out of which 33 persons were placed in qualitative-descriptive evaluation group and 118 persons were placed in quantitative group. Research methodology has been applied and causal-comparative in terms of purpose and nature respectively.Validity and reliability of the instruments were appropriate. Cronbach's alpha coefficient was 0.78 for the researcher-made academic progress questionnaire. In order to analyze the data, independent t-test was used; and Mann-Whitney U test was also used for examining the accuracy of the findings. The results indicated that students' academic progress in quantitative evaluation group (9.24) has been lower than in qualitative evaluation group (10.51). Besides, the results revealed that academic motivation of (all) students in quantitative evaluation group (111.84) has been lower than in qualitative evaluation group (120.27).it is suggested to consider the positive role of qualitative-descriptive evaluation method on academic progress and academic motivation of the elementary students.
\end{abstract}

Keywords: qualitative-descriptive evaluation, academic progress, academic motivation 


\section{Introduction}

Not so long ago, Iran's educational system policymaker's concerns were mainly the quantitative development of the education and it was attempted to respond to widespread and increasing demands of families for childrens' education as much as possible, and to provide the minimum level of education for all children. In other words, officials' concerns at that time were comprised of two basic important matters: first, increasing access to education throughout the country and second, equal access to education in order to establish social justice and eliminate all the educational inequalities in recent years; these concerns have gradually changed from quantitative increase of 'access to education' into the basic and more worthwhile matter of 'quality improvement', and paying attention to quality has become one of the matters policymakers take into account; acting to improve the quality of the process of teaching-learning is undoubtedly more complicated than acting to quantitatively expand it. It is because factors affecting quality improvement are very diverse ranging from improving and reforming in-service training to reforming curricula; all these reforms should lead to the improvement of the quality of learning in the classroom. One of the important factors in this regard and maybe one of the effective factors in all the reforms carried out with the aim of quality improvement is 'educational evaluation'; educational evaluation is considered one of the factors affecting the quality of the process of teaching-learning, which has been drawn the attention of experts in recent years (Hasani, 2009).

In the quantitative approach of teaching-learning, educational evaluation is the last stage of teacher's educational activities and completes all other activities of the teacher. In this stage, teacher measures students' learning outcomes through different methods and techniques, and determines their degree of success in achievement of educational goals. Besides, teacher determines the degree of his/her success in implementing different stages of his/her educational plan through this. It means that he/she can examine previous stages of his/her educational plan, detect his/her work's shortcomings and try to eliminate them in order to achieve educational goals by utilizing the results obtained from students' learning outcomes (Seif, 2003).

Experience of continuous evaluation in $90 \mathrm{~s}$ and plan of qualitative-descriptive evaluation in 2000s are among the reform movements enacted by the Supreme Council of Education in 84 . New approaches of educational evaluation consider a more important role for educational evaluation in the classrooms in addition to the role quantitative evaluation plays in education and educational evaluation; it is a role considered by the teacher more or less in the past. Teachers had realized from experience that classroom evaluation could result in the improvement of learning; therefore, they repeatedly administered exams and used to ask a lot in order to increase learning through repeating lesson topics in the classroom and motivate students to study their lessons. Through a qualitative look, the function of educational evaluation in detecting weaknesses and strengths of teaching-learning activities and giving feedback is considered more, because giving feedback results in the improvement of learning and deeper and more stable learning (Hasani, 2009). 
Evaluation refers to a systematic process for collecting, analyzing and interpreting data in order to determine whether set goals are achieved or are being achieved, and to what extent they have been achieved. Thus in evaluation, the element of how goals and educational expectations are achieved and giving feedback for improving the level of learning process is considered. It is in such a way that the results of evaluations should be applied in the improvement of learning process and educational decision makings; hence without awareness of evaluation components including understanding of goals and educational expectations and signs of the achievement of goals, collecting data, analyzing and interpreting data, judging and making decision, and giving feedback, it is practically impossible to collect and analyze data and judge the achievement of educational expectation and make decision for the guidance of learning towards the achievement of those goals (Hasani, 2009).

There are deficiencies and shortcomings in the traditional-quantitative approach of educational evaluation including: memory training, lack of attention to different areas and levels of education, causing anxiety and undesirable stress in the learners due to final exams, increased repetition of basic grades and wasting educational budget, aiming at final exams instead of learning, lack of attention to mental health in the environment of teaching-learning, lack of developing creativity and creative thinking in learners, lack of developing the spirit of inquiry and criticism, dominance of final exams due to the result-oriented approach to the teaching-learning process, lack of attention to students' efforts and all-round progress, quantitative assessment and ignorance of qualitative assessment, being confined to pencil and paper exams and limited use of other assessment tools. In the traditional approach of evaluation, with the dominance of behavioral perspectives, factors other than the students were considered to be more important in the process of learning and the learner did not have an active and effective role in this process; consequently, education was divided into simple and small steps, because it was believed that complex learning would occur by integrating these small steps (Seif, 2008).

With the emergence and development of cognitive perspectives and its new branches such as constructivism, more complex learnings including thinking, reasoning and inference etc. became important and the active role of student in the process of learning and its high position was emphasized and considered. Therefore, evaluation methods change based on learning through new methods such as performance tests, portfolio and logging etc. in order to be able to create more real situations for evaluation, and the first step is the implementation of descriptive evaluation in elementary schools. In other words, thorough development in life appropriate to global accomplishments in the area of IT and social relations, special skills, useful experiences gained from studying practical assessment and evaluation methods by respected teachers throughout the country and successes of evaluation systems in other countries have provided a situation in which the individuals and the society have new expectations, different from the past, of educational systems. Accordingly, it is required in the current situation to employ methods and tools in educational evaluation, so that the educational systems can respond to these new expectations. Thus considering the drawbacks observed in the process of implementing qualitative-descriptive method, descriptive evaluation method has been successful with regard to the achievement of some goals 
anticipated by the Supreme Council of Education and it has been unsuccessful in many cases. It has been in such a way that in descriptive approach of educational evaluation, the second goal of the specific commission of the Supreme Council of Education, i.e. enhancing the level of mental health, has been successfully achieved; however, other anticipated important goals have not been fully achieved or the conditions for their achievement are not provided so far, such as improvement of students' attitude towards learning, increased mental durability (stability of learning), decreased sensitivity of parents to grades, using process feedback in the path of improving learning, employing different types of evaluation tools etc. (KhoshKholgh and Sharifi, 2006).

Kharazmi (2010) indicated that from the viewpoint of teachers, descriptive evaluation model has had a desirable impact on the improvement of the processes governing teacher's practice of teaching and processes governing student's act of learning. Comparative studies of the impact of two qualitative and quantitative evaluation methods revealed that descriptive evaluation has higher impact than quantitative evaluation on the degree of team work and collaboration as well as the decrease of competition and increase of participation in students' discussions and conversations (Namvar, Rastgoo, Abolghasemi and SeifDerakhshandeh, 2010a).

There has been several studies on the subject of qualitative and quantitative evaluations as well as the impact of these two methods on the process of teaching and learning. For example, Nitko (2010), in his book titled Educational Assessment and Evaluation, stated that these kinds of exams and promoting descriptive evaluation in the classroom persuade and encourage the students to think openly and do things creatively.

Teo, Clarson and Matheieu (2010), in their book titled Designing Effective Instruction, indicated that descriptive evaluation in elementary schools leads to classes free of different stresses and anxieties in academic progress of the students.

Van Aura (2006, cited in Sharifzadeh, 2010) studied the effectiveness of formative evaluation feedback in students' performance and motivation in experimental sciences' class of junior high schools. Results indicated that formative evaluation feedback increases significance in junior high school students' self-efficacy.

Black, Williams and Boston (2002) indicated that formative evaluation greatly affects students' learning in cognitive, social and emotional terms.

Fuchs, Fuchs, Karnes, Hanlett and Katzaroff (1999), in their study titled "Mathematics Performance Assessment in the Classroom: Effects on Teacher Planning and Student Problem Solving", indicated that students of the classrooms guided by performance assessment possess better problem solving skills.

In the study conducted by Kemp and Toperoff (1998) on the subject of students' portfolio assessment (in descriptive evaluation) in England, they concluded that use of portfolio causes the learner to be active and independent, fosters inner motivation in learners and improves achievements, develops communication skills and social relations, provides an opportunity for conversation between the teacher or trainer and the learner, is considered an appropriate 
tool and method for indicating learning, and provides the opportunity to assess all the individuals in disparate and heterogeneous classes.

Mousavi and Maghami (2012), in their study titled "Comparing the Effectiveness of the Two New and Old Educational Evaluation Methods in Elementary Students' Attitude towards Creativity and Academic Progress", indicated that according to the results, except for the interactions in variables of gender, grade and group (new method of evaluation versus old method), there has been a significant difference in attitude towards creativity; girls' performance has been better than boys; fourth grade students have had better performance than fifth grade students and students who were evaluated through the conventional methods have had a more desirable performance in attitude towards creativity rather than those evaluated through the new evaluation method; however, there has been no significant difference in academic progress between two groups.

Another study was conducted by Najafi, Mohammadi, RazmArar and Mohammadzadeh (2012) titled "the Impact of Descriptive and Traditional-Quantitative Evaluations on Second Grade Students' Academic Progress and Exam Anxiety in Educational Year 2011-12”. The results indicated the significance of the differences between academic progress and anxiety with respect to the kind of evaluation in students; and students who were evaluated descriptively have had higher academic progress and lower exam anxiety.

Namvar, Rastgoo, Abolghasemi and SeifDerakhshandeh (2010a), in their study titled "a Comparative Study of the Effectiveness of Implementing Qualitative-Descriptive Evaluation and Traditional Evaluation in Elementary Students' Social Skills", indicated that descriptive evaluation has had a higher impact than quantitative evaluation on the degree of team work and collaboration as well as the decrease of competition and increase of participation in students' discussions and conversations.

Namvar, Rastgoo, Abolghasemi and SeifDerakhshandeh (2010b), in their study titled "Comparing the Role of Descriptive Evaluation in Reducing Anxiety and Increasing Self-Confidence in Elementary Students in Schools Implementing New Method and Traditional Schools", indicated that students of schools implementing qualitative-descriptive evaluation experience less anxiety and more self-confidence than students of traditional schools.

Kharazmi (2010), in his study titled "a Study of the Impact of Qualitative-Descriptive Evaluation Model on the Improvement of the Process of Teaching-Learning of Third Grade Students in Hormozgan Province from the Viewpoint of Teachers", indicated that from the viewpoint of teachers, descriptive evaluation model has had above-average and desirable impact on the improvement of the processes governing teacher's practice of teaching and processes governing student's act of learning. Besides, the impact of descriptive evaluation model on each one of the components of the process governing teacher's practice of teaching and components of processes governing student's act of learning has been desirable from the viewpoint of teachers implementing qualitative-descriptive evaluation, and there has been a significant difference at the level of $95 \%$ between the components of the process governing teacher's practice of teaching and components of processes governing student's act of 
learning based on qualitative-descriptive evaluation; there is a significant difference at the level of $95 \%$ between two groups of teachers implementing qualitative-descriptive evaluation and teachers implementing quantitative evaluation with regard to processes governing the teacher's practice of teaching and it can be said that processes governing teachers' practice of teaching who impalement descriptive evaluation have been better than teachers who implement quantitative evaluation.

Hamedi (2009), in her study titled "Evaluation of the Implementation of Qualitative-Descriptive Evaluation Plan in Semnan Province", indicated that regarding the achievement of goals, 90 out of 96 persons believed in the achievement of goals and 6 persons postponed the achievement of goals to the future. The opinion of the 14 interviewees has been positive about the totality of the plan. Besides, she indicated that most problems in the implementation of qualitative-descriptive evaluation plan include inappropriately distributed human resources (population of the class, parents' education), material resources (checklists and area of the classroom) and supporting facilities (guiding teacher, in-service classes and quality of classes).

Zarei (2008), in his study titled "the Impact of Qualitative-Descriptive Evaluation on Creativity and Learning Collaboration and Academic Performance of Girl and Boy Third Grade Students in Bandar Abbas", indicated that there is a significant difference between degree of students' collaboration in learning in descriptive and traditional methods. But there is no difference between boys and girls in descriptive and traditional methods. Besides, there is a significant difference between students' creativity, and descriptive evaluation system and traditional evaluation system, but there is no significant difference between boys and girls. In the qualitative section, he indicated that collaboration in class, students' interaction with each other and with the teacher, and the discipline governing the class have been higher in the group of qualitative-descriptive evaluation than traditional evaluation group. Besides, in the group of descriptive evaluation, collaboration in class and discipline and interaction with each other and together have been higher among girls than boys.

According to the above materials and rather rich background (rather rich because qualitative evolution has been implemented in Iran for less than a decade), it is intended to comparatively study the academic progress and academic motivation of students in two quantitative and qualitative-descriptive evaluation methods in order to further enrich the related background and to address the role of qualitative evaluation in increase of academic motivation and academic progress from a new aspect.

\section{Research Methodology}

This study has been applied and causal-comparative (ex-post facto) in terms of purpose and method of conduction, and in terms of operation, it compares the impact of two groups of independent variable on dependent variable. It is because the aim of the present study is to comparatively study the impact of two quantitative evaluation and qualitative-descriptive evaluation methods on academic progress and academic motivation of sixth grade students. Thus two quantitative evaluation and qualitative-descriptive evaluation methods are considered independent variables and academic progress and academic motivation are 
considered dependent variables. And the impact of variables such as economic and cultural status, calendar age of students, urban and rural society and students' gender through selecting statistical sample from urban and rural society of Mahidasht region was controlled, and because of the geographical distribution of rural schools and lack of education department's agreement with direct presence of the researcher in the schools, the impact of sixth grade teacher was considered to be the mediating variable. Under such conditions, the present study has been conducted.

\section{Research Instruments}

a)Researcher-made academic progress questionnaire for mathematics: this questionnaire was made by the researcher and contains 18 questions. These 18 questions have been designed based on the levels of Bloom's cognitive domains in three lower levels, middle levels and higher levels. In other words, questions of lower levels of Bloom's cognitive domain include lower levels of 'knowledge and comprehension'; middle levels of cognitive domains include 'application and analysis'; and higher levels of cognitive domains include 'synthesis and evaluation'. These questions were also designed and administered with regard to question designing principles and with reference to 8 chapters of sixth grade mathematics textbook. Its validity has been approved of by the experts and provincial teachers of mathematics. Its reliability has been 0.83 based on total Cronbach's alpha coefficient. Besides, Cronbach's alpha coefficient has been $0.77,0.82$ and 0.69 for questions of lower, middle and higher cognitive levels respectively.

b) Researcher-made academic progress questionnaire for experimental sciences: this questionnaire was made by the researcher and contains 33 questions. These 33 questions have been designed based on the levels of Bloom's cognitive domains in three lower levels (16 questions), middle levels (12 questions) and higher levels (5 questions). In other words, researcher-made paper and pencil performance test for experimental sciences include 33 questions which have been designed and administered with regard to question designing principles and with reference to 14 chapters of sixth grade experimental sciences textbook, in lower levels of 'knowledge and comprehension'; middle levels of cognitive domains include 'application and analysis'; and higher levels of cognitive domains include 'synthesis and evaluation'. Its validity has been approved of by the experts and provincial teachers of experimental sciences. Its reliability has been 0.78 based on total Cronbach's alpha coefficient. Besides, Cronbach's alpha coefficient has been $0.71,0.73$ and 0.67 for questions of lower, middle and higher cognitive levels respectively.

c) Academic motivation scale: this scale was made by Harter (1981) and includes 33 items in 5-point Likert scale. Each one of the items of this scale are answered in 5-pint Likert scale ranging from (1) never to (5) almost always. Reliability and validity of this scale was measured by Bohrani (2009) by using a sample consisted of 198 students (110 boys and 88 girls) of second grade junior high schools in central parts of Shiraz city. Internal consistency coefficients have been in the range of 0.30 and 0.78 through calculating the correlation of each question with total score of scales. Analysis of the factors revealed in scale questions could indicate four factors which show the dimension of inner motivation with high clarity 
and in overall. Sub-scales of inner motivation could also be identified with lower clarity in this analysis. In addition, there relationship of different dimensions of Harter's motivation scale with each other and with scores of academic progress of the students has been as expected, which indicates the validity of the scale. Coefficients of test-retest reliability and Cronbach's alpha calculated for the dimensions and sub-scales of this instrument have been desirable and indicate stability in Iranian students' academic progress measurement (Bohrani, 2009). In the present study, Cronbach's alpha has been 0.76 for this scale.

\section{Research findings}

The hypothesis one of the study states that 'there is a minor difference between academic progress (in lower, middle and higher levels of Bloom's cognitive domains) among sixth grade students in two qualitative-descriptive evaluation and qualitative evaluation methods. Since the distribution of the data related to progress in mathematics is normal, independent t-test has been adopted in order to test this hypothesis. The results are presented in table 1. Statistical assumptions of the study are as follows:

a) Null hypothesis (H0): there is not a minor difference between academic progress (in lower, middle and higher levels of Bloom's cognitive domains) among sixth grade students in two qualitative-descriptive evaluation and qualitative evaluation methods.

b) Alternative hypothesis (H1): there is a minor difference between academic growth (in lower, middle and higher levels of Bloom's cognitive domains) among sixth grade students in two qualitative-descriptive evaluation and qualitative evaluation methods.

Table 1. Results of independent t-test for comparing students' academic progress in two groups of quantitative evaluation and qualitative-descriptive evaluation methods

\begin{tabular}{|c|c|c|c|c|c|c|}
\hline $\mathbf{p}$ & $\mathbf{T}$ & df & $\begin{array}{l}\text { Standard } \\
\text { Deviation }\end{array}$ & Mean & Group & Variable \\
\hline \multirow[t]{2}{*}{0.046} & 2.09 & 149 & 3.09 & 9.24 & quantitative evaluation & Academic progress \\
\hline & & & 3.76 & 10.51 & $\begin{array}{r}\text { qualitative-descriptive } \\
\text { evaluation }\end{array}$ & \\
\hline \multirow[t]{2}{*}{0.086} & -1.776 & 149 & 1.095 & 3.47 & quantitative evaluation & $\begin{array}{r}\text { Lower cognitive } \\
\text { domain }\end{array}$ \\
\hline & & & 1.36 & 3.91 & $\begin{array}{r}\text { qualitative-descriptive } \\
\text { evaluation }\end{array}$ & \\
\hline \multirow[t]{2}{*}{0.054} & -1.958 & 149 & 1.38 & 3.65 & quantitative evaluation & $\begin{array}{r}\text { Middle cognitive } \\
\text { domain }\end{array}$ \\
\hline & & & 1.13 & 3.21 & $\begin{array}{r}\text { qualitative-descriptive } \\
\text { evaluation }\end{array}$ & \\
\hline \multirow[t]{2}{*}{0.095} & -1.680 & 149 & 1.07 & 2.56 & quantitative evaluation & $\begin{array}{r}\text { Higher cognitive } \\
\text { domain }\end{array}$ \\
\hline & & & 1.24 & 2.93 & $\begin{array}{r}\text { qualitative-descriptive } \\
\text { evaluation }\end{array}$ & \\
\hline
\end{tabular}


As it is seen in table 1, there is a significant difference between the mean for students' progress in mathematics in two groups of quantitative evaluation and qualitative-descriptive evaluation methods $(\mathrm{p}<0.052 ; \mathrm{f}=3.837)$. It means that the mean for students' progress in mathematics has been lower in the group of quantitative evaluation than qualitative evaluation. However, there has been no significant difference between progress in mathematics in lower, higher and middle cognitive levels. According to the results presented in the above table, alternative hypothesis (H1) is generally confirmed.

The hypothesis two of the study states that 'there is a minor difference between academic motivation (inner and outer) among sixth grade students in two qualitative-descriptive evaluation and qualitative evaluation methods. Since the distribution of the data related to academic motivation is normal, independent t-test has been adopted in order to test this hypothesis. The results are presented in table 2. Statistical assumptions of the study are as follows:

a) Null hypothesis (H0): there is not a minor difference between academic motivation (inner and outer) among sixth grade students in two qualitative-descriptive evaluation and qualitative evaluation methods.

b) Alternative hypothesis (H1): there is a minor difference between academic motivation (inner and outer) among sixth grade students in two qualitative-descriptive evaluation and qualitative evaluation methods.

Table 2. Results of independent t-test for comparing students' academic motivation in two groups of quantitative evaluation and qualitative-descriptive evaluation methods

\begin{tabular}{cccccrr}
\hline $\mathbf{P}$ & $\mathbf{t}$ & $\mathbf{d f}$ & $\begin{array}{r}\text { Standard } \\
\text { deviation }\end{array}$ & Mean & Group & Variable \\
\hline 0.002 & -3.132 & 149 & 14.42 & 111.82 & $\begin{array}{r}\text { quantitative } \\
\text { evaluation }\end{array}$ & $\begin{array}{r}\text { Academic } \\
\text { motivation }\end{array}$ \\
& & 10.64 & 120.27 & $\begin{array}{r}\text { qualitative-descriptive } \\
\text { evaluation }\end{array}$ & \\
\hline 0.002 & -3.183 & 149 & 7.88 & 57.77 & $\begin{array}{r}\text { quantitative } \\
\text { evaluation }\end{array}$ & a- inner \\
& & & 5.42 & 61.97 & $\begin{array}{r}\text { qualitative-descriptive } \\
\text { evaluation }\end{array}$ & \\
\hline 0.005 & -2.866 & 149 & 7.09 & 54.042 & $\begin{array}{r}\text { quantitative } \\
\text { evaluation }\end{array}$ & b- outer \\
& & & & 58.30 & $\begin{array}{r}\text { qualitative-descriptive } \\
\text { evaluation }\end{array}$ & \\
\hline
\end{tabular}

As it is seen in table 2, there is a significant difference between the mean for students' (total) academic motivation, inner academic motivation and outer academic motivation in two groups of quantitative evaluation and qualitative-descriptive evaluation methods $(\mathrm{p}<0.116$; $\mathrm{f}=$ 
2.505). It means that the mean for students' (total) academic motivation, inner academic motivation and outer academic motivation has been lower in the group of quantitative evaluation than qualitative evaluation. According to the results presented in the above table, alternative hypothesis (H1) is confirmed.

\section{Discussion and Conclusion}

According to the analysis results, there is a minor difference between academic progress (in lower, middle and higher levels) among sixth grade students in two qualitative-descriptive evaluation and qualitative evaluation methods. The results of independent $t$-test indicated that there is a significant difference between the mean for students' academic progress in two groups of quantitative evaluation and qualitative-descriptive evaluation. It means that the mean for students' progress in mathematics has been lower in the group of quantitative evaluation than qualitative evaluation. However, there has been no significant difference between progress in mathematics in lower, higher and middle cognitive levels.

There has been no study on the impact of these two methods on students' academic progress. But this finding can confirm the research results of Najafi et al. (2012), who concluded that students, who were evaluated through descriptive method, have had higher academic progress, by studying the impact of descriptive and traditional-quantitative evaluation methods on academic progress and exam anxiety in second grade students in Tehran.

In explanation of this finding, it can be said that this can be due to emotional impact of low and high grades among students with which they are faced in quantitative evaluation. For example, a student who has received half a score lower than his/her peer in mathematics, might consider him/herself inferior to the other student and this affects his/her next grade for mathematics. However, if students are qualitatively evaluated, they usually do not feel a difference between themselves and their peers, and this might reduce negative emotions in them about lower grades.

Regarding the academic progress, research findings indicated that there is a minor difference between academic motivation (inner and outer) among sixth grade students in two qualitative-descriptive evaluation and qualitative evaluation methods. The results of independent t-test revealed that there is a significant difference between the mean for students' academic motivation in two groups of quantitative evaluation and qualitative-descriptive evaluation methods. It means that the mean for students' (total) academic motivation, inner academic motivation and outer academic motivation has been lower in the group of quantitative evaluation than qualitative evaluation.

Since there has been no study conducted on the impact of these two evaluation methods on academic motivation, it can be said that this finding confirms research findings of Zarei (2008) who indicated that collaboration and participation in class, students' interaction with each other and with the teacher and the discipline governing the class have been higher in the group of qualitative-descriptive evaluation than traditional evaluation.

In explanation of this finding, it can be said that quantitative evaluation method, due to the evaluation criteria exist in it, usually is accompanied by students' reduced academic 
motivation. It is because students evaluate themselves more based on the obtained grade in this method, and sometimes unhealthy covert competition occurs between them; and this may cause problems in their motivation to participate in class activities and positive attitude towards educational activities. But in descriptive evaluation method, students usually do not compare themselves with other based ion their grade and individuals' similarities are usually more in descriptive groups; and this further motivates them to participate in the class and perform educational activities. Regarding the inner and outer motivations, it can be said that because of the importance of both inner and outer motivations during the elementary period, both inner and outer motivations have been higher in the group of descriptive evaluation. Even though the outer motivation of students should have been lower in the group of descriptive evaluation, because the students participating in this study were all elementary students, it can be said that presence of both inner and outer motivations in them for learning are equally important.

Given the limitation of statistical population in this study, it is suggested to the educational planners and researchers to measure these components throughout the country and in all education levels in order to comprehensively study the role of qualitative evaluation in academic progress and academic motivation of students, so that education officials and the statistical population of the education department including teachers, instructors, parents and students can realize the importance of this matter. Of course, in future studies, all the control and mediating variables should be included to gain more reliable results.

In addition, since the results of the study indicated that students of the group of quantitative evaluation have had lower academic motivation, it is suggested to adopt descriptive evaluation method and highlight its advantages in order to increase students' academic motivation. For the easier application of descriptive evaluation method, it is also suggested to produce checklists and grading scales of observational method for different concepts and goals of the learning units in various courses of elementary period in a consistent manner and in bulk or to design them by the provincial and regional educational groups, and to provide schools and teachers with them at the beginning of educational year to enrich the process of teaching-learning. Finally, it is suggested to study the motivation and attitude of teachers towards the use of the evaluation method and to adopt other instrument in order to collect data regarding descriptive evaluation.

\section{References}

Black, P., Williams, S., \& Boston, J. (2002).Working inside the black box.Phi Delta Kappan.ERIC, data full text library.

Cruickshank, D. R., Jenkins, D. B., \& Metcalf, K. K. (2009). The act of teaching.5th Edition. Boston: McGraw Hill.

Hurlock, E. (2003). Child development. New York: McGrew Hill. International Technology Education Association, (ITEA). Advancing Excellence in Technological Literacy: Student Assessment, Professional Development, and Program Standards. Reston, Virginia: ITEA. 
Hamedi, H. (2009). Evaluation of the implementation of qualitative-descriptive evaluation plan in Semnan Province (MA thesis).Alzahra University.

Hasani, M. (2009). Qualitative descriptive evaluation. Tehran: Moaser Publications.

Kharazmi, M. (2010). A study of the impact of qualitative-descriptive evaluation model on the improvement of the process of teaching-learning of third grade students in Hormozgan Province from the viewpoint of teachers in educational year 2010-11 (MA thesis).Teacher Training University.

KhoshKholgh, I., \&Sharifi, H. (2006).Assessment of pilot implementation of descriptive evaluation in elementary schools in some parts of Iran (2005-06). Journal of Education, 88, 117-148.

Kavousian, J. (2011). Relationship of environmental, Educational factors with school well-being: role of Psychological needs, motivational self-regulation and academic emotions ( $\mathrm{PhD}$ dissertation). Kharazmi University.

MohagheghMoeen, M. (2003).Assessment of the pre-pilot implementation of descriptive evaluation plan. Office of Educational and Academic Evaluation.

Mansour, M., Dadsetan, P., \& Rad, M. (2006).Dictionary of psychology. Tehran: Zharf Publications.

Mousavi, S. M., \&Maghami, H. (2012).Comparing the effectiveness of the two new and old educational evaluation methods in elementary students' attitude towards creativity and academic progress.Originality and Creativity in Human Sciences, 2, 125-146.

Namvar, Y., Rastgoo, A., Abolghasemi, A., \&SeifDerakhshande, S. (2010a). A comparative study of the effectiveness of implementing qualitative-descriptive evaluation and traditional evaluation in elementary students' social skills.Teaching and Evaluation (Educational Sciences), 3, 143-152.

Namvar, Y., Rastgoo, A., Abolghasemi, A., \& SeifDerakhshande, S. (2010b). Comparing the role of descriptive evaluation in reducing anxiety and increasing self-confidence in elementary students in schools implementing new method and traditional schools.Knowledge and research in Educational Sciences, 27, 199-212.

Najafi, M., Mohamamdifar, M., RazmAra, \& Mohammadzadeh, S. (2011). The impact of descriptive and traditional-quantitative evaluations on second grade students' academic progress and exam anxiety in educational year 2011-12.Research Plan, Tonekabon Education Department.

Nitko, A. J. (2010). Educational assessment and evaluation (3thed). New jersey: Merrill, prentice-hall.

Pintrich, P. R. (2003). A motivational science perspective on the role of student motivation in learning and teaching contexts. Journal of Educational Psychology, 95(4), 667-686.. http://dx.doi.org/10.1037/0022-0663.95.4.667 


\section{Macrothink}

Journal of Management Research

ISSN 1941-899X 2015, Vol. 7, No. 5

Seif, A. (2003). Educational measurement, assessment and evaluation. Tehran: Doran.

Seif, A. (2011). Modern educational psychology. Tehran: Doran.

Teo, E., Clarson, S., \& Matheieu, J. (2010).Designing effective instruction. USA: Wiley.

Trow, W. C. (2000). Psychology in teaching and learning. New Delhi: Eurasia Publishing House (Pvt.) Ltd.

Zarei, E. (2009). The impact of qualitative-descriptive evaluation on creativity and learning collaboration and academic performance of girl and boy third grade students in Bandar Abbas. Educational Sciences (Journal of Educational Sciences and Psychology), 5(2), 72-92. 